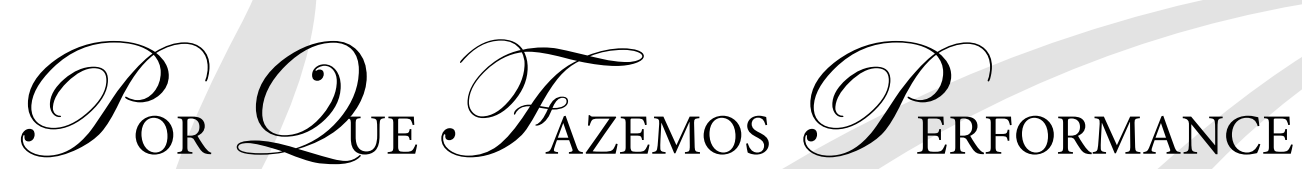

E ATIVISMO FEMINISTA?

“Por Qué Hacemos Performance y Activismo Feminista?”

\author{
Stela Fischer* \\ Programa de Pós-Graduação em Artes Cênicas \\ Universidade de São Paulo
}

RESUMO: O texto identifica e analisa duas ações cênicas ativistas do Coletivo Rubro Obsceno: Eu abortei (2014) e O que te prende, mulher? (2014-2016), ambas apresentadas como intervenção urbana na cidade de São Paulo. Considerando a análise e cartografia dessas ações - que lançam posicionamentos políticos na construção de poéticas cênicas, e cujas premissas giram em torno de visibilizar as subjetividades das mulheres -, enfatizo a importância da reflexão crítica a partir do próprio fazer artístico. Compartilho a experiência de atuação enquanto artista das artes cênicas e, acima de tudo, identifico os motivos pelos quais ainda se faz necessário promover ativismos feministas.

Palavras-chave: Ativismo feminista; performance feminista; teatro de mulheres.

RESUMEN: El texto identifica y analiza dos acciones escénicas y activistas del Colectivo Rubro Obsceno: Eu abortei (2014) y O que te prende, mulher? (20142016), ambas presentadas como intervención urbana en la ciudad de São Paulo (Brasil). Teniendo en cuenta el análisis y cartografía de estas acciones - que lanzan posiciones políticas en construcciones poéticas escénicas, y cuyas premisas giran en torno a visualizar las subjetividades de las mujeres - enfatizo la importancia de la reflexión crítica a partir del propio hacer artístico. Comparto la experiencia de trabajo como artista de las artes escénicas y, sobre todo, identifico las razones por las que todavía es necesario promover el activismo feminista.

Palavras-clave: activismo feminista; performance feminista; teatro de mujeres. 


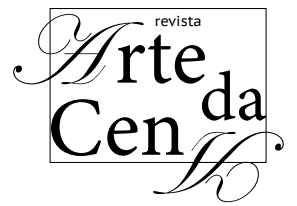

Há alguns anos venho me dedicando ao ativismo artístico, em especial às ações cênicas que são ao mesmo tempo poéticas, estéticas e políticas, que tratam dos direitos das mulheres e das minorias políticas. Não faz sentido para mim realizar uma arte que não esteja vinculada às demandas do meu entorno social. E a realidade do Brasil - assim como a maioria dos países da América Latina - é ainda hostil em relação às mulheres e demais grupos invisibilizados, sobre os quais perpetuam-se os discursos e articulações políticas que naturalizam a violência e precariedade dos modos de existir. Ainda mais em tempos como este que vivemos. Tempos de governo ilegítimo no Brasil, no qual pode-se antever tentativas de recrudescimento dos dispositivos de controle biopolíticos e de subjetividades, escamoteados nas medidas de corte dos gastos públicos ${ }^{1}$ que reforçam os padrões da heteronormatividade patriarcal, machista, racista, capitalista, cristã e homofóbica. Tempos nos quais se faz necessário resistir.

É no ativismo artístico que desenvolvo a minha resistência. Posiciono-me enfaticamente a partir do lugar de ativista feminista. Eu não refuto essa denominação. Inúmeras são as questões pendentes e perpetradas que reeditam as temáticas clássicas dos feminismos levantadas por Simone de Beauvoir no livro O segundo sexo, publicado em 1949, e que ainda são atuais tanto no Brasil como em diversos países nos quais a discriminação e a violência contra mulheres seguem culturalmente arraigadas. Reivindicações são constantemente "re-historicizadas", tais como a autonomia em relação ao corpo e à sexualidade; a descriminalização e legalização do aborto; o enfrentamento à violência e à cultura do estupro; a equidade salarial; a maior representatividade das mulheres em cargos políticos e institucionais; as desigualdades sociais envolvendo conflitos de classe e raça; enfim, todas as pautas urgentes, em especial no nosso contexto latino-americano. Hoje, no entanto, estas reivindicações são ampliadas e entrelaçadas a outras questões sociais e políticas, envolvendo as multiplicidades identitárias e subjetivas inter-relacionais ${ }^{2}$. Os desafios dos feminismos e suas lutas são contínuos e devemos ainda desestabilizar os binarismos, bem como “[...] formular novas constelações para pensar a normatividade, se quisermos proceder de maneiras intelectualmente abertas e compreensivas a fim de compreender e avaliar o mundo em que vivemos" (BUTLER, 2015b, p. 207).

E é, também, na intersecção de trânsitos possíveis entre as atuais teorias feministas, a criação artística e o ativismo, entre a performance e o teatro, que me interessa fazer uma arte feita de fissuras e aporias. Trata-se de convocar as identidades marginalizadas de diversas mulheres para tomar o centro das discussões sob os vieses 
político, ético e poético. Demarcar articulações do pensamento decolonial a partir das políticas do corpo e das artes como espaço de experimentação identitária em que as diferenças são aceitas, estimuladas, e as relações de poder e opressão são denunciadas.

Desenvolvo um trabalho junto ao Coletivo Rubro Obsceno, agrupamento teatral criado em 2013 na cidade de São Paulo, a partir dos encontros do The Magdalena Project no Brasil ${ }^{3}$. Composto exclusivamente por mulheres artistas da performance, da dança e do teatro tem a finalidade de tratar as questões sobre a legitimação de direitos das mulheres no contexto social brasileiro. Juntas promovemos grupos de estudos sobre a mulher na contemporaneidade, abordando textos de Gayatri Spivake Paul Beatriz Preciado etc.; workshops com artistas convidadas; festivais, como a Mostra ObsCENAs: encontro de mulheres artistas, que teve sua primeira edição em novembro de 2014 e contou com a presença de Julia Varley, atriz do Odin Teatret e fundadora do The Magdalena Project; e criações artísticas. Por exemplo, estivemos em parceria com a performer mexicana, na criação da performance "Para aquelas que não mais estão", memorial às vítimas de feminicídio na América Latina e, também, denúncia poético-cênica da violência contra as mulheres. A performance participou da II Bienal Internacional de Teatro da Universidade de São
Paulo em 2015, e do X Encuentro do Hemispheric Institute of Performance and Politics, em Santiago do Chile, julho de 2016. Em sua trajetória, o Rubro Obsceno realiza projetos artísticos sociais sob a perspectiva de um teatro voltado ao empoderamento de diferentes grupos de mulheres, como: mulheres soropositivas (Projeto ++ Mulheres, em parceria com a ONG Ecos Comunicação e Sexualidade, 2010-2013), mulheres em situação de violência (parceria com o Centro de Referência da Mulher - Casa Eliane de Grammont, 2015), mulheres com mais de 60 anos (Projeto [des]velhecer, SESC Santana, 2016), e, mais recentemente, mulheres em situação de cárcere (Projeto Mulheres Possíveis, junto ao Coletivo Teatro Dodecafônico, 2016/2017).

Para uma melhor compreensão sobre os motivos pelos quais o Rubro Obsceno desenvolve trabalhos ativistas e artísticos "afetados" pela realidade das mulheres brasileiras, apresento a seguir duas ações do coletivo que foram realizadas como intervenção artística urbana na cidade de São Paulo.

A primeira é o solo Eu abortei (2014). É uma ação-protesto ante os meios de controle sobre o corpo das mulheres brasileiras e da sua sexualidade. Vale sempre lembrar e insistir que a proibição ao aborto "retira às mulheres o domínio sobre seu corpo, restringindo também seu 
direito à privacidade na decisão sobre questões de forte relevância ética e moral para os indivíduos" (BIROLI \& MIGUEL, 2014, p. 44). Mesmo sem números oficiais, milhares de mulheres morrem anualmente no Brasil por fazer abortos clandestinos; outras sofrem discriminações e violência por não ter atendimento legal no sistema de saúde público ao darem entrada em hospitais em situação de abortamento ${ }^{4}$.

Como consequência, as mulheres convivem com uma prática silenciosa, seguida de culpabilização, humilhação, isolamento, riscos de saúde e morte, porque o aborto é uma prática usual entre as mulheres. Pesquisas recentes apontam que uma em cada quatro mulheres já praticou aborto no Brasil (GODINHO \& VENTURI, 2013, p. 195). O Código Penal Brasileiro prevê a prisão de um a três anos para a mulher que abortar intencionalmente. Apenas em três casos a interrupção é legalmente permitida no Brasil: quando a gestação oferecer risco de morte para mãe; quando a gravidez decorre de um estupro; e quando o feto é anencéfalo. E há articulações políticas envolvendo governantes - muitos filiados a partidos que têm vínculos com o fundamentalismo cristão - que querem violar, inclusive, os direitos das mulheres, constitucionalmente assegurados pelo Artigo 128 do Código Penal. Ou seja, vivemos momentos de anacronismos em relação aos direitos das mulheres e à pauta da descriminalização e legalização do aborto. No nosso Legislativo essa perspectiva torna-se cada vez mais combatida. Isso se deve muito a certa bancada composta de deputados e senadores fundamentalistas que obstrui os "direitos individuais das mulheres, compromete a laicidade do Estado e, com isso, a cidadania e a construção de uma sociedade plural e democrática” (BIROLI\& MIGUEL, 2014, p. 126). Vide as adesões e tentativas de aprovação de inúmeros projetos de lei, como o Estatuto do Nascituro (PL 487/07), que prevê que o aborto seja proibido em qualquer circunstância, atribuindo ao embrião o status jurídico e moral de pessoa nascida e viva; o seu desdobramento na "bolsa estupro", assistência financeira para a gestante que tenham sido vítima de estupro; e o PL 5069/2013 , que restringe o atendimento pelo Sistema Único de Saúde às vítimas de violência sexual. Estas só poderão receber atendimento hospitalar após registro de queixa na polícia e exame de corpo de delito pelo Instituto Médico Legal. Além disso, o projeto pede o aumento de pena para profissionais da saúde que praticarem o aborto e restringe a distribuição das chamadas “pílulas do dia seguinte”. Operações de poder como estes PLs são aqui destacadas para enfatizar que a falta de laicidade real do Estado legitima a violência contra as mulheres. E essas medidas ilustram bem o quanto a sexualidade e as mulheres brasileiras têm sido cada vez mais vigiadas e a discussão sobre a legalização do aborto, sem dúvidas, está blindada no nosso atual 
Congresso Nacional.

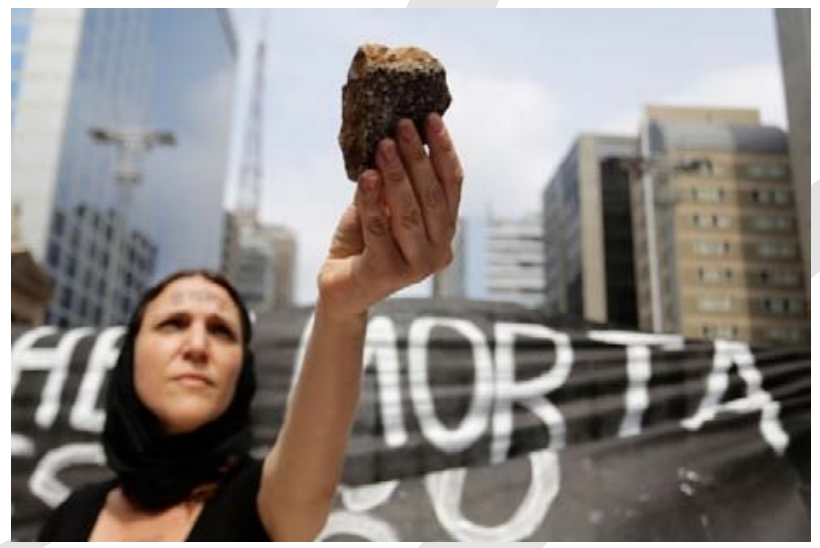

FIGURA 1. Stela Fischer em Eu abortei. São Paulo, setembro de 2014. Foto: divulgação

A decisão pelo aborto não é fácil. Gera ansiedade, insegurança, medo, culpa, dor. Na maioria das vezes é uma decisão que produz sequelas para toda a vida de uma mulher. Nesse sentido, a intervenção urbana Eu abortei é um "abraço" simbólico, um acolhimento às mulheres (e aos homens) que em algum momento de suas vidas tiveram que tomar essa - muitas vezes difícil decisão. Seja pela intimidação de se praticar um crime, ou pela dificuldade de realizar o procedimento de forma segura. Ou, ainda, e de forma mais severa, pela falta de amparo emocional e apoio no período que segue após o abortamento, pois não se pode falar abertamente sobre o assunto em âmbito social.

$\mathrm{Na}$ ação, estou em silêncio, sentada diante de um monte de pedras. Carimbo meu corpo com os dizeres "eu abortei", enquanto o público é estimulado a interagir comigo e executar ações a partir de algumas orientações/instruções de uso que estão escritas num cartaz: "1. Pegue uma pedra; 2. Julgue; 3. Atire”. O público tem a opção de atirar a pedra em mim ou de se deixar carimbar. São inúmeras as reações: abraços apertados, choros contidos, gritos de apoio, compartilhamento de experiências traumáticas. Mas, em geral, há uma comoção no instante em que me deixam imprimir em seus corpos algo que já está para sempre marcado: o aborto é uma marca na vida de uma pessoa - tanto para as mulheres quanto para os homens - que levamos até a morte.
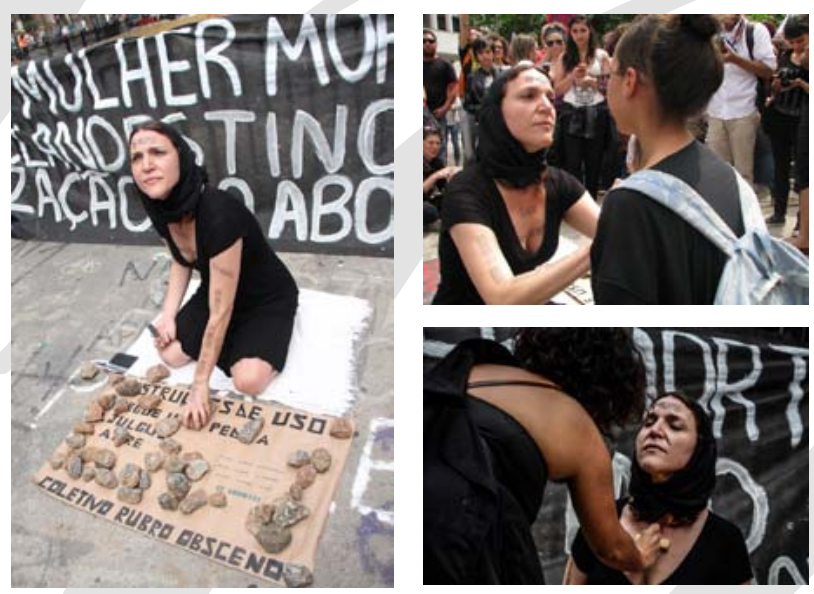

FIGURAS 2, 3 e 4. Stela Fischer em Eu abortei. Fotos: Clarissa Wolff e Gabriela Biló

Realizar esta intervenção é deliberadamente um ato de exposição e risco. Estou num espaço público, evocando um assunto que ainda é tomado como tabu e divide opiniões, incitando a espectador, transeunte da cidade, a julgar-me e tomar uma atitude sobre mim, diante da minha autorrevelação. Neste contexto, é realizada a confissão como uma prática de exame de si que "não 
consiste numa crítica de si, ou, com efeito, na interiorização de normas reguladoras, mas se torna uma maneira de se entregar a um modo público de aparição" (BUTLER, 2015a, p. 147). Ao me expor e me colocar à berlinda de suas repostas, evoco no público o seu gesto ético. Se o julgamento se faz inútil, a ação torna-se um convite ao diálogo sensível de um tema que não se pode falar. Um

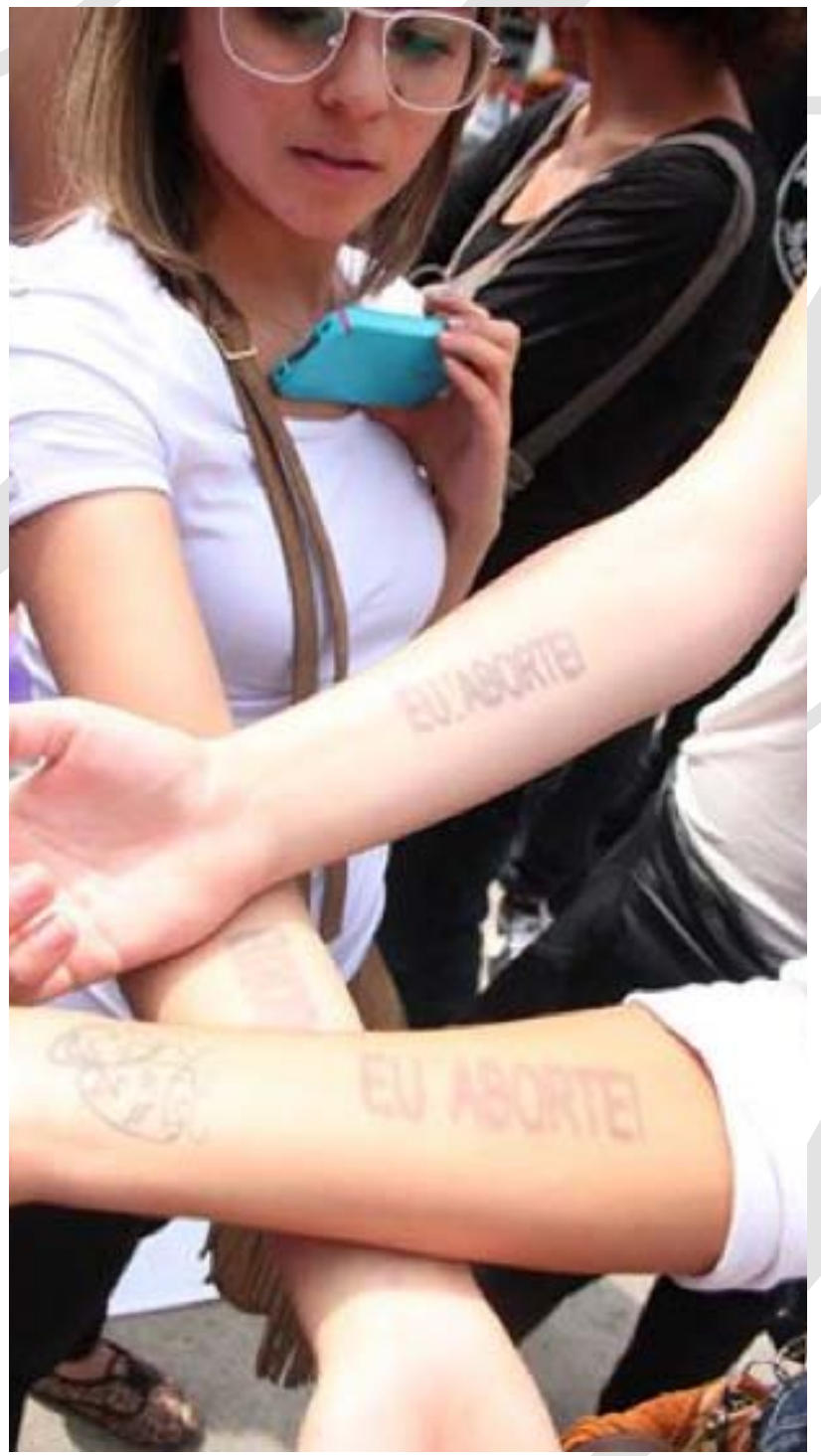

FIGURAS 5, 6, 7 e 8. Eu abortei.

Fotos: Luciana Ramin e Gabriela Biló diálogo sem palavras, assim como é abortar para muitas mulheres, feito de silêncios. E a maioria dos espectadores que se aproxima para participar da ação, recebe a pedra que eu ofereço, decide por deixar-se marcar e permanece em contato comigo, olhando nos meus olhos, em silêncio. Acolhidos um no outro.
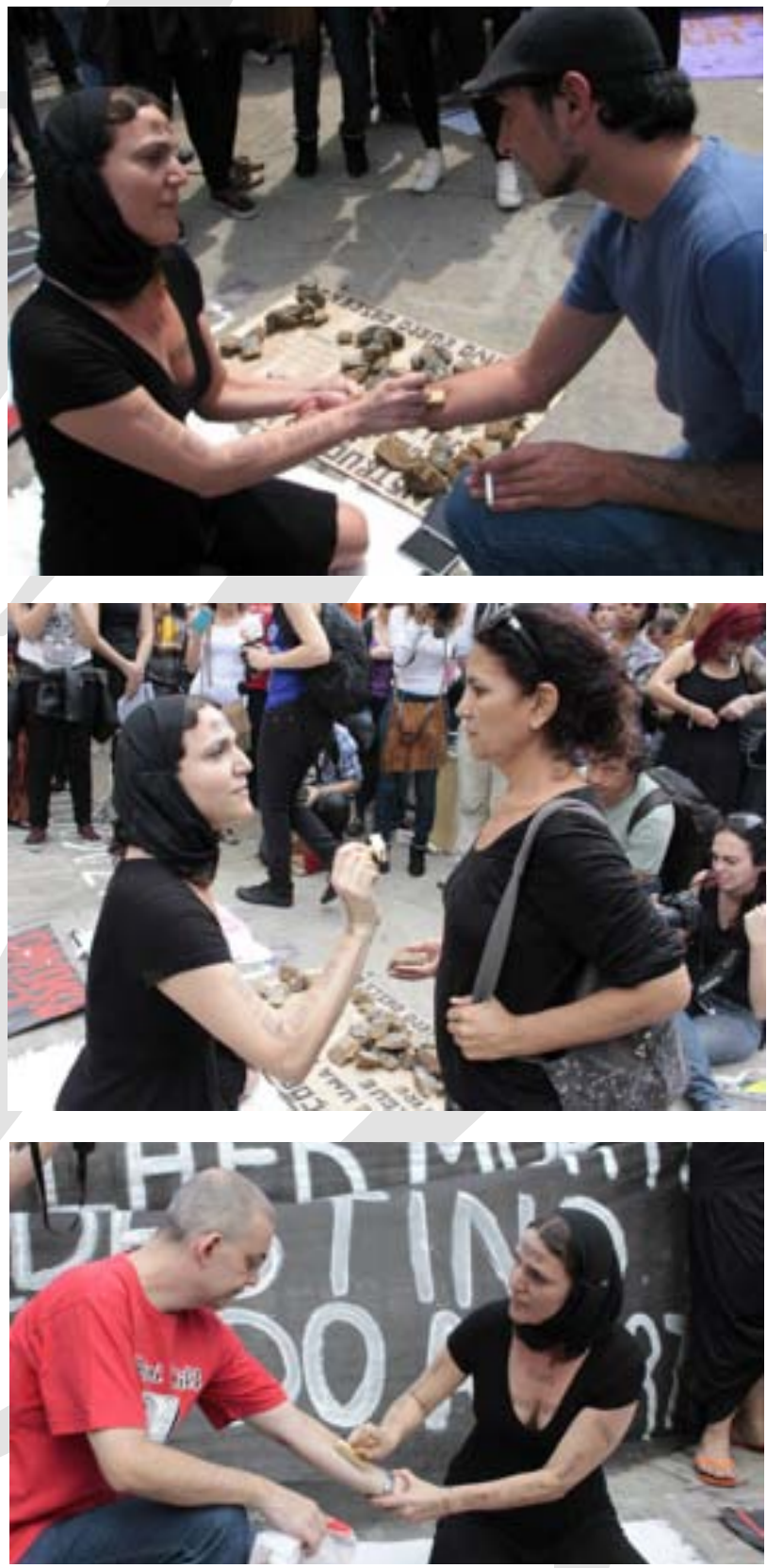

Stela Fischer - Por que fazemos performance e ativismo feminista?

Arte da Cena, Goiânia, v. 3, n. 1, p. 08-20, Jan-jun/2017

Disponível em: http://www.revistas.ufg.br/index.php/artce 


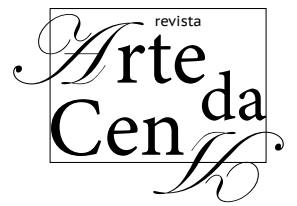

A segunda intervenção artística urbana do Rubro Obsceno é O que te prende, mulher?, com o intuito de propor uma "libertação simbólica” das inúmeras amarras que nós mesmas nos colocamos ou aceitamos apenas por sermos mulheres. É uma reflexão cênica tratada com leveza e humor para nos inteirar criticamente dos atos que reproduzimos cotidianamente e que reforçam os dispositivos biopolíticos de produção das diferenças de gênero. Nossa intenção é provocar as mulheres participantes para voltar à atenção para si e identificar em suas próprias atitudes e discursos formas de opressão de gênero naturalizadas que elas mesmas reproduzem sem questionar. É um deslocar-se do seu próprio lugar de vítimas para produzir subjetividades "delirantes" que desmoronem e combatam todo sistema de opressão pautado no capital e nas diferenças de gênero, raça e classe:

Uma prática política que persiga a subversão da subjetividade de modo a permitir um agenciamento de singularidades desejantes deve investir o próprio coração da subjetividade dominante, produzindo um jogo que a revela, ao invés de denunciá-la. Isso quer dizer, ao invés de pretendermos a liberdade (noção indissoluvelmente ligada à consciência), temos de retomar o espaço da farsa, produzindo, inventando subjetividades delirantes que, num embate com a subjetividade capitalística, a façam desmoronar (ROLNIK, 1989, p. 30).

Somos três performers (Leticia Olivares, Monica Siedler e Stela Fischer) emaranhadas por fios e fitilhos nos quais fazemos o gesto repetido de dar nós. Convidamos mulheres para participar de nossa performance, orientando-as também a partir das seguintes instruções de uso: "1. Pegue uma folha e uma caneta; 2. Escreva um nó que você mesma, como mulher, se prende; 3. Leia em voz alta; 4. E desate esse nó". Damos uma prancheta com papel e caneta para a participante escrever a resposta que quiser. Ficamos com o seu texto e em troca lhe entregamos um nó, bem apertado que tem que desatar. Ao realizar com sucesso o ato de desatar o nó, vibramos, abraçamos, festejamos a sua "libertação".
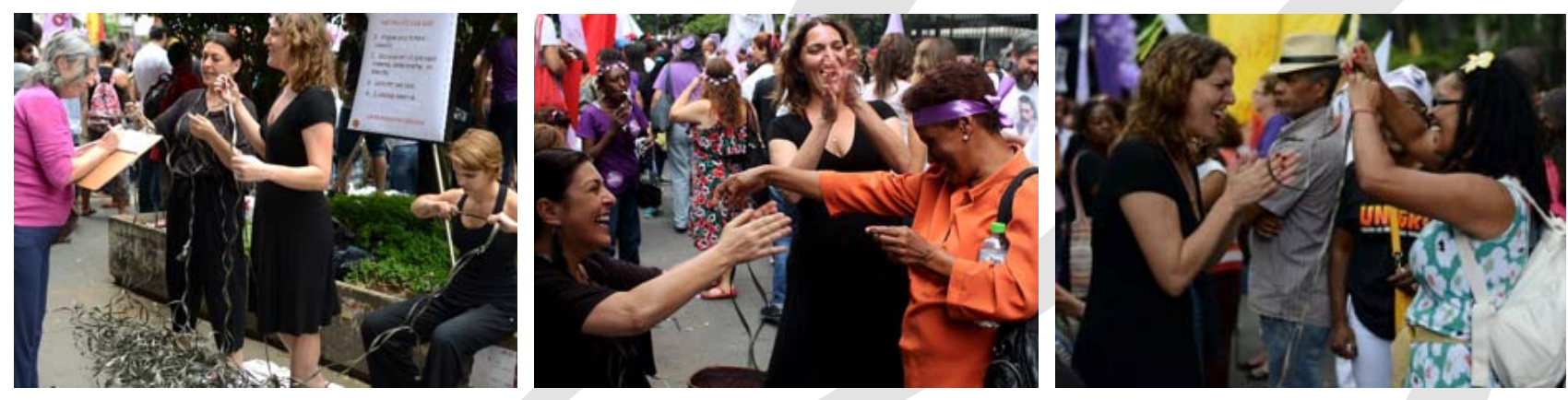

FIGURAS 9, 10 e 11: Stela Fischer, Leticia Olivares e Monica Sielder na intervenção O que te prende, mulher?. São Paulo, março de 2015. Fotos: Roderick Steel e Clarissa Olivares.

Stela Fischer - Por que fazemos performance e ativismo feminista?

Arte da Cena, Goiânia, v. 3, n. 1, p. 08-20, Jan-jun/2017

Disponível em: http://www.revistas.ufg.br/index.php/artce 
Como respostas à pergunta "O que te prende, mulher?", tivemos as seguintes respostas: "A sexualidade, quero me libertar!!” (Vanessa, 22 anos); "A falta de liberdade e de escolha com o meu corpo" (Brenda, 16); “O que me prende como mulher é ainda hoje o meu marido não me deixar trabalhar fora" (Cleide, 45); "Dizem que eu tenho que casar” (Bárbara, 26); “O que me prende é a falta de compreensão do meu pai” (Nina, 18); "A cultura da chapinha" (Marilda, 30); "Sofrer preconceito" (Cátia, 39); "Você não vai passar um batom nem por um brinquinho?” (Marina, 18); "Sou impedida de usar o que quero e o que me faz bem” (Raquel, 27); “O machismo” (Silvana, 42); "Moralismo" (Luiza, 50); "Desigualdade e violência” (Lucimar, 47); “Estupro em família” (Taís, 25); "A cobrança em relação ao meu papel na família" (Fátima, 46); "Me sentir impotente" (Vivian, 26); "A falta de coragem” (Raíssa, 18); "Insegurança” (Tainá, 17); “Ter medo” (Isadora, 20); “Preciso me impor mais e reconhecer minha força" (Marian, 23); “Ter que fazer tudo e sempre ouvir que está errado" (Tatiana, 25); "Não ter os mesmos direitos que os homens" (Giovana, 11); "Ganhar salário menor do que os homens" (Cristina, 53); “Ser mãe e me preocupar com as pessoas" (Daiana, 30); “A responsabilidade perante os outros” (Natália, 31); “Casamento compulsório” (Rosângela, 37); e “Ser muito sozinha pra tudo" (Carla, 40) (Material de acervo do Coletivo Rubro Obsceno).
Nota-se nas respostas que a opressão às mulheres ainda está muito atrelada aos afazeres domésticos, à repressão do corpo e da sexualidade, à violência sexual muitas vezes em âmbito familiar, aos papeis sociais de representação de gênero impostos pelos dispositivos sociais e, principalmente, à presença do homem como aquele que oprime. Com essa ação construímos redes temporárias para operar um momento de troca, interação e compartilhamento de subjetividades: "Qual é a nossa responsabilidade em relação àqueles que não conhecemos, em relação àqueles que parecem testar nosso senso de pertencimento ou desafiar normas disponíveis de semelhança?" (BUTLER, 2015b, p. 61). Todos os “nós" apontados, todas as amarras enunciadas pelas mulheres com quem nos relacionamos na ação descrita também são as nossas amarras. Estamos falando de um lugar comum. Com a intervenção acionamos um espaço sutil de pertencimento que desafia as normas da semelhança. E o nosso compromisso com elas reside no acolhimento que é o nosso gesto político. $\mathrm{Na}$ rua, pedimos um minuto de atenção. E desse breve instante, juntas, abre-se um espaço para falar de si, de revelar queixas, de jogar e brincar com a sensação de libertação e cura. Gera-se um campo de afetos capaz de promover um posicionar-se sobre a forma como habitamos e/ou desejamos habitar os nossos mundos enquanto mulheres, principalmente e em relação às 
normas excludentes com as quais temos que lidar cotidianamente. Nosso ativismo também está na escuta, no acolhimento e na receptividade. Assim como Eleonora Fabião define suas ações, nas quais a receptividade transforma o corpo em campo:
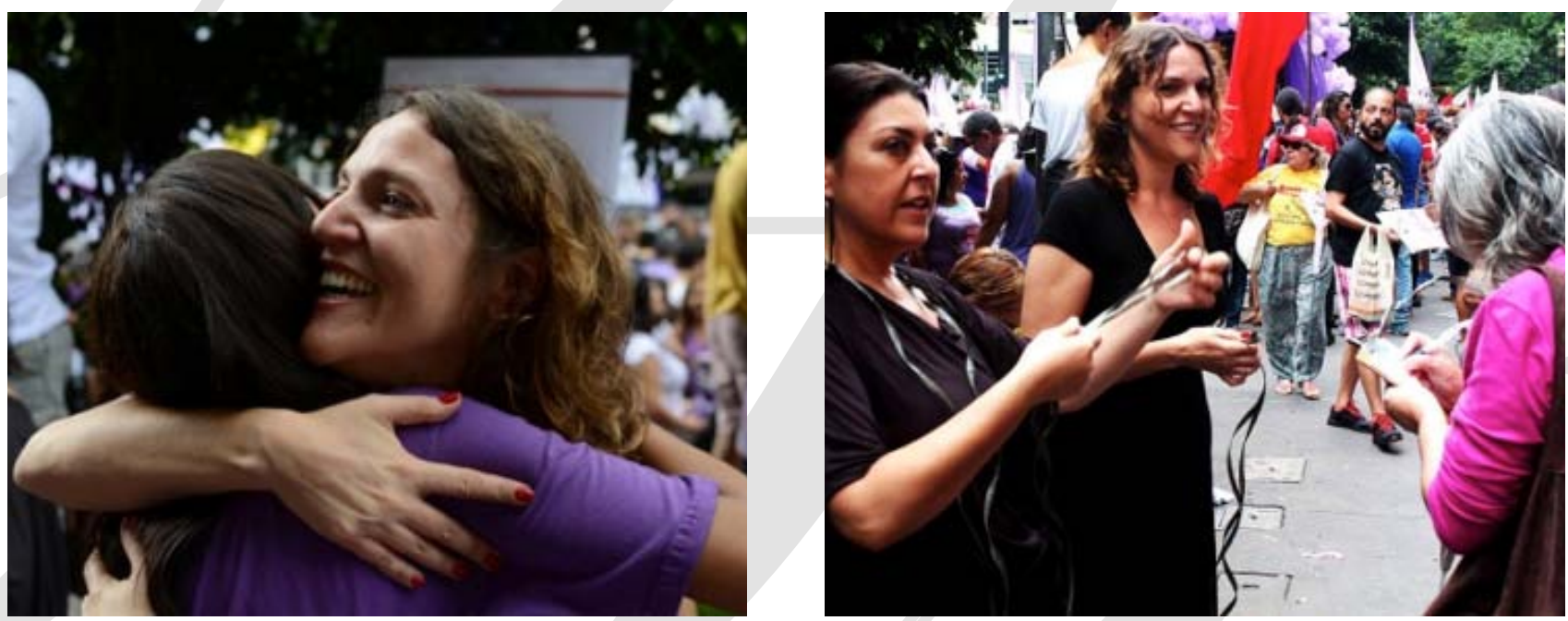

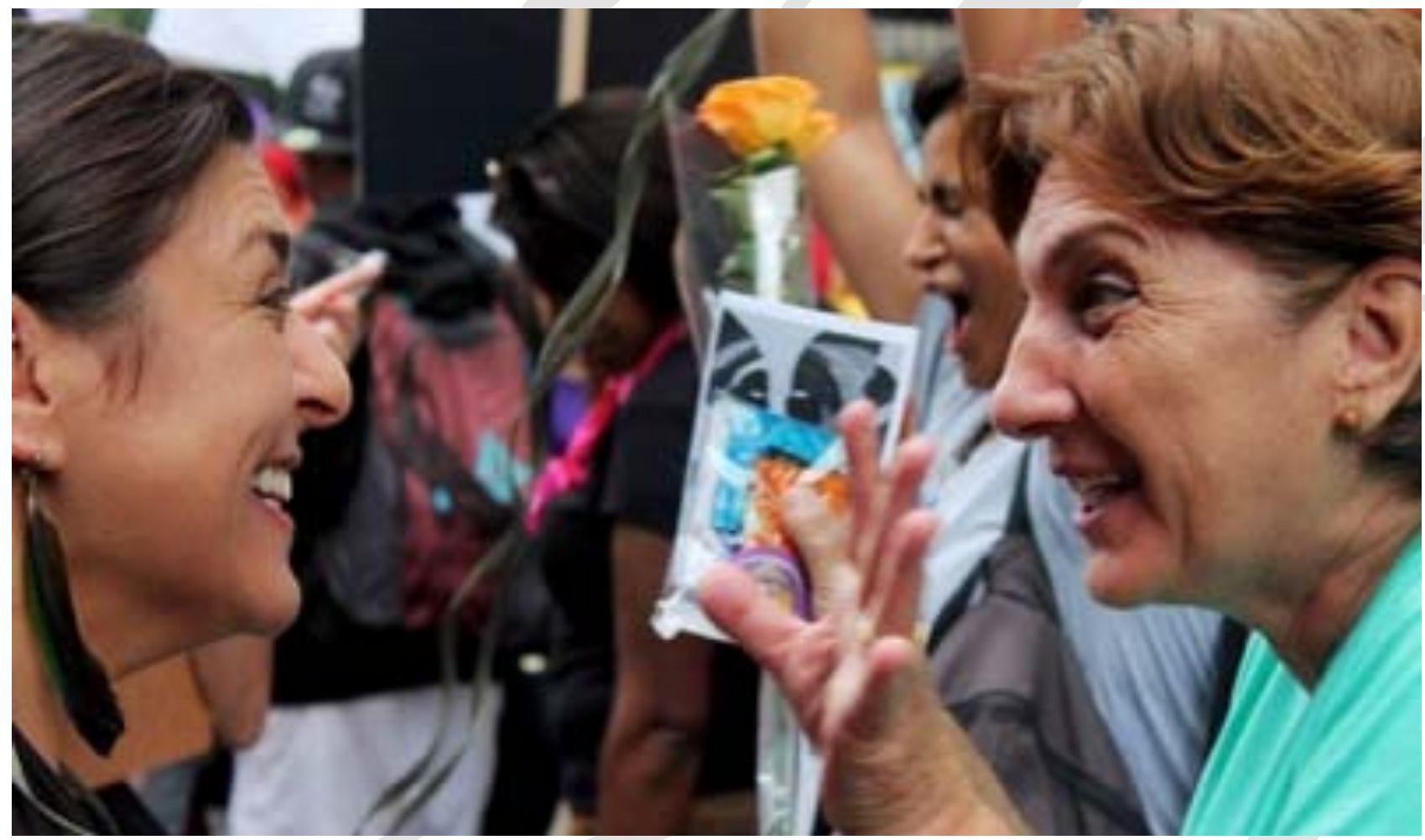

FIGURAS 12, 13 e 14: Intervenção O que te prende, mulher? Fotos: Roderick Steel e Clarissa Olivares.

Stela Fischer - Por que fazemos performance e ativismo feminista?

Arte da Cena, Goiânia, v. 3, n. 1, p. 08-20, Jan-jun/2017

Disponível em: http://www.revistas.ufg.br/index.php/artce 


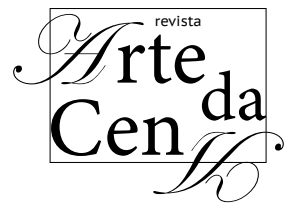

A intervenção $O$ que te prende, mulher? também foi apresentada na reinauguração da Casa Eliane de Grammont, em São Paulo, quando iniciamos um trabalho voluntário de aulas de expressão e teatro com as mulheres vítimas de violência e frequentadoras desse espaço, em outubro de 2015. E na saída da Estação de Metrô Tiradentes, em março de 2016, como parte da programação da Ocupação Mulheres, Performance e Gênero, promovida pela Oficina Cultural Oswald de Andrade, parceria entre os coletivos Rubro Obsceno e Teatro Dodecafônico; na Jornada Internacional de Teatro Feito por Mulheres, organizada pelo Magdalena Project 3a. Geração, em 3 de dezembro de 2016, na Oficina Cultural Oswald de Andrade, também na capital paulista.

\section{E então...}

\section{Estas duas intervenções do Rubro Obsceno} são um ato de aproximação entre as mulheres/ performers e mulheres/público que compartilham um momento de aproximações e "inversão de papeis", pois à medida que as ações transcorrem, as participantes tomam à frente do acontecimento tornando-se agentes criadoras da ação e nós, performers, nos identificamos com suas questões, queixas e dores. Isso faz da ação uma ocasião de socialização ao mesmo tempo artística e reivindicatória, no qual afetamos e nos deixamos afetar. Ao produzirmos uma experiência artística que ocupa o espaço urbano, apropriamo-nos de questões da ordem do dia em relação às falas das mulheres ali presentes e promovemos um espaço de convívio no qual a interatividade é condição para que essas vozes ganhem espaço. Propiciamos o que Ileana Diéguez (2011) aponta como espaço liminar entre performance e ativismo e construímos a nossa maneira um ato político próprio, sem deixar de ser poético.

Assim, Eu abortei e O que te prende, mulher? figuram a construção de uma resposta à pergunta/ título deste artigo, quando procuro justificar o motivo pelo qual fazemos uma arte e ativismo feminista ainda nos dias de hoje. Sem dúvida o que nos move - e aqui eu me incluo, apesar do distanciamento investigativo - é a perplexidade em relação aos tratamentos políticos, sociais e culturais quando se trata dos assuntos relacionados às mulheres brasileiras. Nós não representamos o ativismo. A partir da cena, também nós protestamos. Estamos em defesa dos feminismos, mas não de forma ingênua. Bem sabemos que tanto o feminino como o masculino são produtos de uma economia reguladora do gênero, do sexo e que movimenta todo um "capitalismo dos gêneros" (PRECIADO, 2008), incluindo aqui as formas tidas como dissidentes, ou subversivas do sistema de heterossexualidade compulsória. O nosso conceito de feminismo é uma construção particular pautada em leituras e estudos, nas 


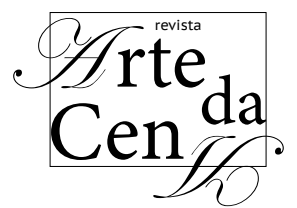

nossas experiências de vida, nas idiossincrasias a elas inerentes, em nossas relações pessoais, no nosso posicionamento político e, principalmente, em nossa prática artística. Um feminismo próprio cheio de divergências, rupturas, dissensões e fragmentações. Somos ativistas sem perder de vista a criação estética. O nosso ativismo artístico é resultado de processos de simbolizações e corporificações de memórias e testemunhos de situações de traumas e violência, de dominação e colonialidades, do resgate de constituição de identidades que formam, ao final, a construção de subjetividades políticas. E acreditamos em diferentes possibilidades estéticas, poéticas e discursivas para transcender a condição de vitimização das mulheres, articulando a partir de nossas criações outros temas numa dinâmica capaz de envolver expressões múltiplas, principalmente quando se trata de expressões de construção de identidades com valores sociais que desestabilizem as construções de discursos opressores.

A cena é o nosso manifesto.

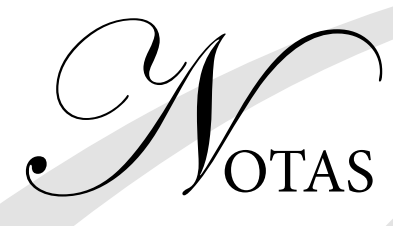

Por exemplo, de acordo com o portal do orçamento do Senado Federal, o governo Temer reduziu em $61 \%$ verba para atendimento à mulher em situação de violência em 2017. Sem contar que na sua gestão, os cargos políticos e institucionais são ocupados na sua maioria por homens (brancos!). Isso afeta a representatividade das mulheres no Congresso Nacional e, consequentemente, o avanço na legislação e na criação de medidas que favoreçam as mulheres. E esse quadro assevera-se ao considerar a ausência das mulheres negras e indígenas na gestão Temer.

Como, por exemplo, o direito à visibilidade social das mulheres transexual e transgênero; os movimentos das mulheres do campo contra as práticas insidiosas do agronegócio e a luta pela reforma agrária; as jovens estudantes secundaristas nas ocupações das escolas diante da discrepante reestruturação do sistema educacional brasileiro; as causas ambientais do ecofeminismo; a saúde e melhores condições de atendimentos às mulheres de baixa renda; e assim por diante.

The Magdalena Project (1986) é uma rede internacional de artistas mulheres do teatro com sede em Cardiff (País de Gales). Sua meta principal é o intercâmbio e incentivo à reflexão crítica sobre a mulher no teatro contemporâneo. Trata-se de uma ampla rede mundial que aglutina criadoras de diferentes localidades e culturas (Índia, Dinamarca, Cuba, Espanha, Colômbia, Peru, USA, Argentina, Austrália, Nova Zelândia, Alemanha, Bélgica, Brasil, por exemplo). Promove encontros periódicos que objetivam agregar mulheres artistas em 
atividades de intercâmbio de experiências, como workshops, debates, demonstrações de trabalhos e apresentações artísticas. No Brasil temos quatro edições do The Magdalena Project: Solos Férteis Festival Internacional de Mulheres no Teatro, em Brasília (DF), organizado por Luciana Martuchelli; Multicidade - Festival Internacional de Mulheres nas Artes Cênicas, no Rio de Janeiro (RJ), por Paola Vellucci; Magdalena 3a. Geração, em Jundiaí (SP), por Luiza Bitencourt; e Vértice Brasil, em Florianópolis (SC), por Barbara Biscaro, Glaucia Grigolo, Marisa Naspolini e Monica Siedler.. Informações no site: www.themagdalenaproject.org.

4 Basta lembrarmos o caso ocorrido em fevereiro de 2015, em São Bernardo (SP), de uma jovem de 19 anos que chegou ao hospital com hemorragia pós-aborto, causada por ingestão de medicação. Ela foi hostilizada pelo próprio médico que a manteve algemada à cama até a chegada da polícia. O médico violou o Artigo 73 do Código de Ética Médica que estabelece normas de sigilo profissional. A jovem foi autuada em flagrante e seu processo corre, podendo ficar até três anos detida. O Ministério da Saúde possui uma norma que zela pelo atendimento humanizado a pacientes em situação de abortamento, com privacidade e confidencialidade de informações. Disponível em:

< h t t p : / / w w w 1.fol ha.uol.com.br / cotidiano/2015/02/1592839-medico-chama-policiaapos-atender-jovem-que-fez-aborto-na-grande-sp. shtml>. Acesso, março de 2017.

5 A "bolsa estupro", de autoria dos então deputados federais Luiz Bassuma (PT-BA) e Miguel Martini (PHS-MG), é uma assistência financeira para as gestantes que tenham sido vítimas de estupro e que decidam levar sua gravidez adiante, ao invés de abortar. Nesse caso, o pai terá direito de registrar a criança, ser o responsável pela pensão alimentícia e, consequentemente, de visitar a criança. O projeto também inviabiliza pesquisa com células-tronco e fertilização in vitro.

O PL 5069/2013, de autoria do ex-Presidente da Câmara, o criminoso e condenado Eduardo Cunha (PMDB-RJ), restringe o atendimento pelo Sistema Único de Saúde às vítimas de violência sexual (Lei 12.845/13).

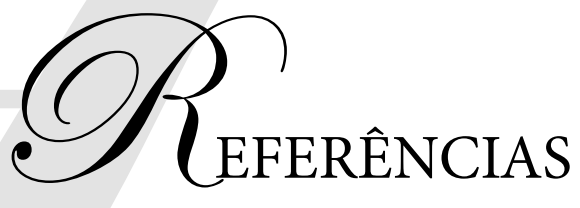

BEAUVOIR, Simone de. O segundo sexo. Volume 1 e 2. Rio de Janeiro: Nova Fronteira, 1980.

BIROLI, Fávia; MIGUEL, Luis Felipe. Feminismo e política: uma introdução. São Paulo: Boitempo, 2014.

BUTLER, Judith. Problemas de gênero: feminismos e subversão da identidade. Rio de Janeiro: Civilização Brasileira, 2008.

BUTLER, Judith. Relatar a si mesmo: critica da violência ética. Belo Horizonte: Autêntica Editora, 2015a.

BUTLER, Judith. Quadros de guerra: quando a vida é passivel de luto? Rio de Janeiro: Civilização brasileira, 2015 b.

DIÉGUEZ, Ileana. Prácticas de visibilidad. Ethos, teatralidad y memória. In: ZAPATA, Miguel Rubio. El cuerpo ausente (performance política). Lima: Grupo Cultural Yuyachkani, 2008.

DIÉGUEZ, Ileana. Cenários Liminares: teatralidades, performances e política. Uberlândia: EDUFU, 2011. 
FABIÃO, Eleonora. Performance e teatro: poéticas e políticas da cena contemporânea. Revista Sala Preta, v. 8, 2008. Disponível em: $<$ http://www.revistas.usp.br/salapreta/article/ viewFile/57373/60355>. Acesso dez. 2016.

FABIÃO, E.; LEPECKI, A. (Orgs.). Ações Eleonora Fabião. Rio de Janeiro: Itaú Cultural, 2015.

GODINHO, Tatau; VENTURI, Gustavo (orgs.). Mulheres brasileiras e gênero nos epsaços público e privado: uma década de mudanças na opinião pública. São Paulo: Editora Fundação Perseu Abramo, 2013.

PRECIADO, Beatriz. Texto Younqui. Madrid: Espasa, 2008.

ROLNIK, Suely. Cartografia Sentimental. Transformações contemporâneas do desejo. São Paulo: Estação Liberdade, 1989.

ROLNIK, Suely. Geopolítica da cafetinagem. 2006. Disponível em: http://eipcp.net/transversal/1106/rolnik/pt. Acesso mar. 2016.

SPIVAK, Gayatri C. Pode o subalterno falar? Belo Horizonte: Editora UFMG, 2010.
* STELA FISCHER é doutora em Artes Cênicas na Universidade de São Paulo, Mestre em Artes/Teatro pela Universidade Estadual de Campinas. Autora do livro Processo Colaborativo e Experiências de Companhias Teatrais Brasileiras (Hucitec, 2010). Coordena na cidade de São Paulo o Coletivo Rubro Obsceno, um agrupamento de mulheres artistas com a finalidade de discutir as questões de gênero nas artes da cena. E-mail: stelafis@terra.com.br

Artigo submetido em: 31/03/2017

Aprovado em: 22/05/2017 